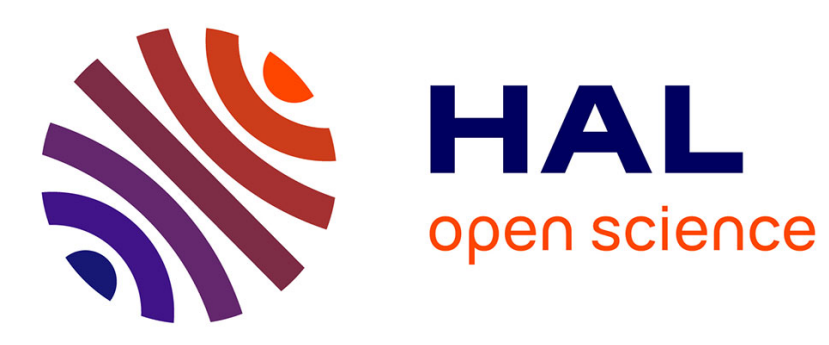

\title{
Spray-gun deposition of catalyst for large area and versatile synthesis of carbon nanotubes
}

Aurelien Gohier, Ki Hwan Kim, Evgeny Norman, Louis Gorintin, Paolo

Bondavalli, Costel Sorin Cojocaru

\section{To cite this version:}

Aurelien Gohier, Ki Hwan Kim, Evgeny Norman, Louis Gorintin, Paolo Bondavalli, et al.. Spray-gun deposition of catalyst for large area and versatile synthesis of carbon nanotubes. Applied Surface Science, 2012, 258, pp.6024-6028. 10.1016/j.apsusc.2012.02.115 . hal-00793869

\section{HAL Id: hal-00793869 \\ https://hal.science/hal-00793869}

Submitted on 2 Mar 2013

HAL is a multi-disciplinary open access archive for the deposit and dissemination of scientific research documents, whether they are published or not. The documents may come from teaching and research institutions in France or abroad, or from public or private research centers.
L'archive ouverte pluridisciplinaire HAL, est destinée au dépôt et à la diffusion de documents scientifiques de niveau recherche, publiés ou non, émanant des établissements d'enseignement et de recherche français ou étrangers, des laboratoires publics ou privés. 


\title{
Spray-gun deposition of catalyst for large area and versatile synthesis of carbon nanotubes
}

\author{
A. Gohier ${ }^{\mathrm{a}, *}$, K.-H. Kim ${ }^{\text {a }}$, E.D. Norman ${ }^{\mathrm{a}}$, L. Gorintin ${ }^{\mathrm{b}}$, P. Bondavalli ${ }^{\mathrm{b}}$, C.S. Cojocaru ${ }^{\mathrm{a}}$ \\ a Laboratoire de Physique des Interfaces et des Couches Minces, Ecole Polytechnique, route de Saclay 91128 \\ Palaiseau Cedex, France \\ b Thales Research and Technology France, D128 91767 Palaiseau Cedex, France
}

\begin{abstract}
ABSRACT: Spray gun deposition technique was investigated for large area deposition of nanocatalysts. In particular, we studied iron chloride salts solutions as catalyst precursor for the synthesis of carbon nanotubes (CNTs). Iron chloride salts are shown to decompose upon thermal annealing into Fe(III) oxide based species that make it suitable for further growth of various carbon nanotube structures. Depending on the spraying process, versatile synthesis of 2-D single-walled carbon nanotube network as well as vertically aligned carbon nanotubes arrays on functional substrates can be achieved. Such simple process for the preparation of CNT-based architecture opens new perspectives in the field of thin-film transistor and nanostructured electrodes.
\end{abstract}

\author{
Keywords:: Vertically aligned \\ carbon nanotubes Single walled \\ carbon nanotube network Spray \\ gun deposition \\ Iron chloride, Thin film \\ transistor
}

\footnotetext{
* Corresponding author. Tel.: +33 169334356.

E-mail address: costel-sorin.cojocaru@polytechnique.edu .
}

\section{Introduction}

The quasi-1D structure of carbon nanotubes (CNTs) has fascinated the scientific community over the past 20 years due to the resulting outstanding physical and chemical properties. Notably, their remarkable electronic transport, huge specific surface area and high aspect ratio make them very attractive for a wide range of applications, such as thin film transistor [1], cold cathode [2], chemical sensing [3] or electrochemical electrode [4].

For most of these potential applications, CNTs must be synthesized directly onto functional substrates, which obviously imply great technological challenges. Since their discovery in 1991 [5], much effort have been undertaken to provide high control of the CNT growth. Up to now, catalytic chemical vapor deposition (CCVD) appears as the most promising technique since it allows to control both the location of the CNTs as well as, to some extent, their structural features (diameter, length) [6,7]. CVD synthesis requires the use of catalyst nanoparticles onto which carbon nanotubes nucleate and grow. These catalytic clusters are preferentially made of transition metal (Fe, Ni, Co) [8] and are usually obtained by metal thin film dewetting upon temperature. Another method for the catalyst preparation consists of using metal salts as precursors. Few studies have investigated this alternative for the growth of CNTs. Choi et al. demonstrated that iron chloride could be reduced in situ in solution to form particle that further deposit onto surface [9]. Kind et al. used $\mathrm{Fe}(\mathrm{III})$-containing gel-like catalyst to pattern CNT growth by microcontact printing [10]. Spin-coating or drop casting iron-based salt solutions have also been successfully used to grow multi-walled or single-walled CNTs [9,11-13].
Here, we study spray technique to deposit iron chlorides(III) as precursor for the growth of CNTs. We find this technique very versatile since the amount of catalyst deposited onto substrates could be easily tuned by either varying the salt concentration or the spraying parameters. As a result, using this method, we show that vertically aligned carbon nanotubes array or in-plane growth of 2-D network can be achieved on alumina or aluminum coated substrates. We emphasize that spray is a cost effective method that can provide catalyst preparation in ambient atmosphere without limitation in terms of surfaces deposition.

\section{Experimental}

Sprayable catalyst solutions with various concentrations $\left(5.10^{-5} \mathrm{M}, 5.10^{-4} \mathrm{M}\right.$ and $\left.5.10^{-3} \mathrm{M}\right)$ were prepared by sonicating $\mathrm{FeCl}_{3} \cdot 6 \mathrm{H}_{2} \mathrm{O}$ in ethanol. A fixed volume $(30 \mathrm{~mL})$ of each $\mathrm{FeCl}_{3} \cdot 6 \mathrm{H}_{2} \mathrm{O}$ solution was deposited using spray gun technique over $\mathrm{Al}_{2} \mathrm{O}_{3}(50 \mathrm{~nm}) / \mathrm{SiO}_{2}(300 \mathrm{~nm}) / \mathrm{Si}$ substrates or aluminum $(30 \mathrm{~nm})$ coated stainless steel foils (50 J.Lm). The sprayer gun was mounted on a stage that could translate in $\mathrm{x}, \mathrm{y}, \mathrm{z}$ directions. During the spraying process, the gun follows a serpentine line along $80 \mathrm{~mm} \times 80 \mathrm{~mm}$ 
square to ensure uniformity in deposition rate. The substrate holder was kept at temperature higher than $200{ }^{\circ} \mathrm{C}$ to evaporate as fast as possible the solvent droplets when hitting the substrate. Unfortunately we were not able to precisely estimate iron nominal thickness deposited onto substrates since a large and unknown part of the aerosol may deposit out of the predefined $80 \mathrm{~mm} \times 80 \mathrm{~mm}$ square.

From as-deposited iron chloride salt, carbon nanotubes were synthesized using hot-wire CVD system as described in detail elsewhere [14]. CNT growth was performed using $\mathrm{CH}_{4} / \mathrm{H}_{2}$ mixture ( $\left.{ }^{\circ} \mathrm{H}_{2}=50 \mathrm{sccm},{ }^{\circ} \mathrm{CH}_{4}=50 \mathrm{sccm}\right)$. In this work, we focus on the effect of iron salt concentration on the CNT growth in the case of two different synthesis conditions. We played on the synthesis temperature and pressure to favor either the growth of single-walled carbon nanotubes $\left(800^{\circ} \mathrm{C}, 25\right.$ mbar) or multi-walled carbon nanotubes $\left(600^{\circ} \mathrm{C}, 50 \mathrm{mbar}\right)$.

X-ray photoelectron spectroscopy (XPS) was carried out to study iron salt evolution upon temperature annealing. The pass energy was set at $30 \mathrm{eV}$ and the energy scale of the spectra was calibrated by setting $\mathrm{Al} \mathrm{2} \mathrm{p}^{3 / 2}$ peak at from the alumina substrate at $75.5 \mathrm{eV}$.

Carbon nanotubes morphology was investigated by Scanning electron microscopy (SEM) (SEM; HITACHI S 4800) and transmission electron microscopy (TEM; Jeol 2010F). The carbon nanotubes structural quality was analyzed by high-resolution confocal Raman microscope (Labram HR800; HORIBA Jobin Yvon) in the normal incident backscattering configuration.

\section{Results and discussion}

Before proceeding to CNT growth, the behavior of iron chloride salts upon thermal annealing was analyzed by XPS. Fe 2p and $\mathrm{Cl} 2 \mathrm{p}$ peaks of as-sprayed iron chloride are displayed in Fig. 1 (black line). Quantitative analysis reveals low $\mathrm{Cl} / \mathrm{Fe}$ atomic ratio of 0.77 instead of 3 as expected $\left(\mathrm{FeCl}_{3}\right)$. After thermal annealing at $700{ }^{\circ} \mathrm{C}$ (Fig. $1 \mathrm{~d}$ and e - red line), chlorine can no more be detected while Fe 2p peak shape remains unchanged with slightly lower intensity. The low percentage of chloride species before annealing suggests that temperature during spray deposition is sufficient to drive a partial decomposition of $\mathrm{FeCl}_{3} \cdot 6 \mathrm{H}_{2} \mathrm{O}$. After in situ annealing at $700{ }^{\circ} \mathrm{C}$ during $10 \mathrm{~min}$, a total decomposition of iron chloride is achieved. The broad Fe 2 $\mathrm{p}^{3 / 2}$ component (FWHM $\sim 3 \mathrm{eV}$ ) located at $711.4 \mathrm{eV}$ and

$711.2 \mathrm{eV}$ before and after annealing respectively is well consistent with high spin $\mathrm{Fe}(\mathrm{III})$ compounds [15]. This means that $\mathrm{FeCl}_{3} \cdot 6 \mathrm{H}_{2} \mathrm{O}$ decomposition does not yield iron metal and chlorine but may produce hydrogen chloride and iron oxide and/or hydroxide species (with $\mathrm{Fe}(\mathrm{III})$ state). We suppose that iron oxide is further reduced to metallic state when exposed to the synthesis atmosphere [8].

SEM images of as-deposited iron salt as a function of the solution concentration are displayed in Fig. 1a-c. For low concentration $\left(5.10^{-5} \mathrm{M}\right)$, single or interlaced ring-structures can be distinguished. When the concentration increases $\left(5.10^{-4} \mathrm{M}\right)$ the ring-structures appear connected by catalyst network. For the higher concentration $\left(5 \cdot 10^{-3} \mathrm{M}\right)$ a very smooth surface is observed.
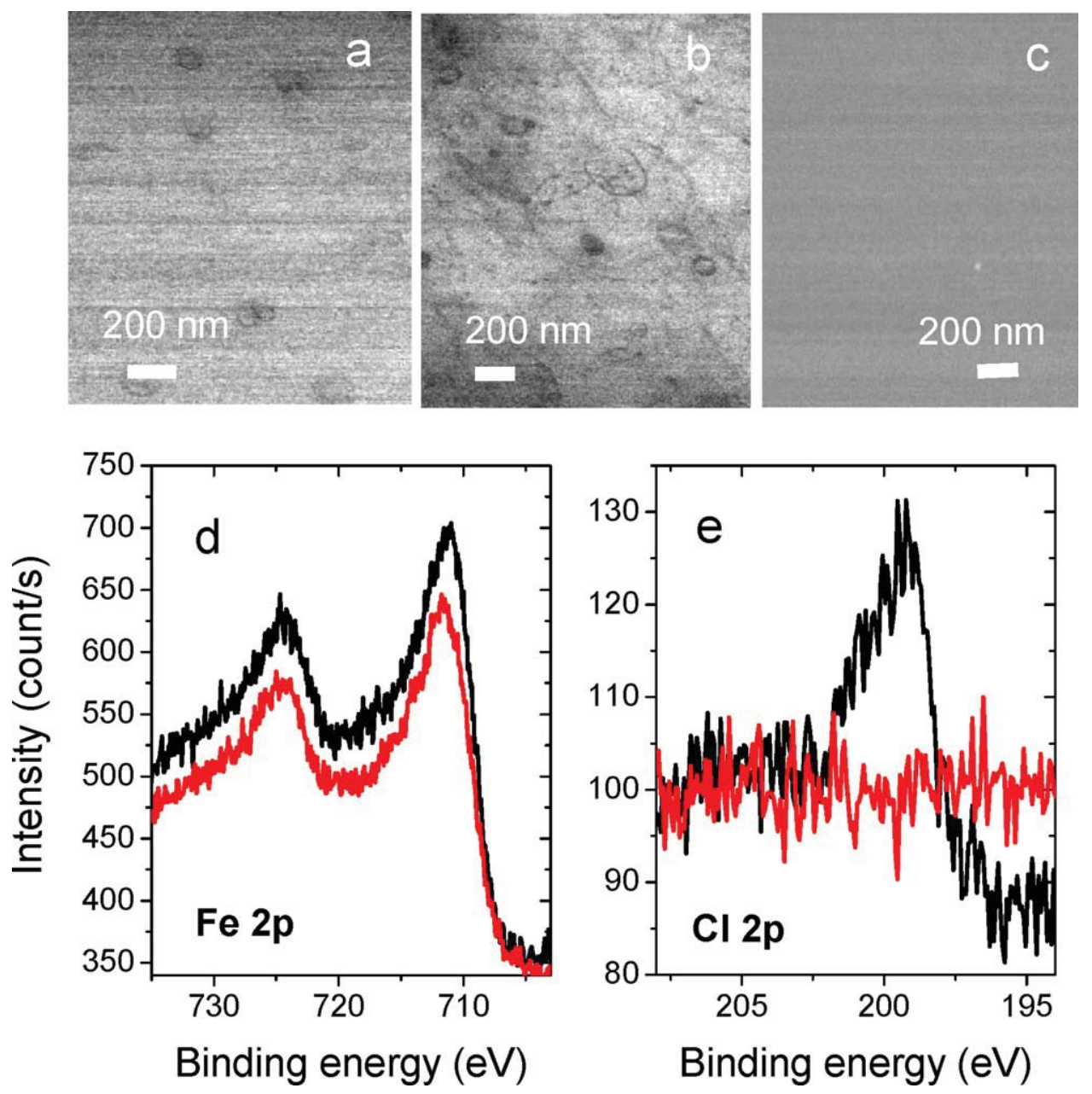

Fig. 1. SEM picture of as-deposited iron chloride salts using: (a) $5.10^{-5} \mathrm{M}$, (b) $5.10^{-4} \mathrm{M}$ and (c) $5.10^{-3} \mathrm{M}$ solutions. (d) XPS Fe $2 \mathrm{p}$ and $\mathrm{Cl} 2 \mathrm{p}$ narrow scan of iron salts as-deposited by spray (black line) and (e) in situ annealed iron salts at $700{ }^{\circ} \mathrm{C}$ (red line). (For interpretation of the references to color in this figure legend, the reader is referred to the web version of the article.) 


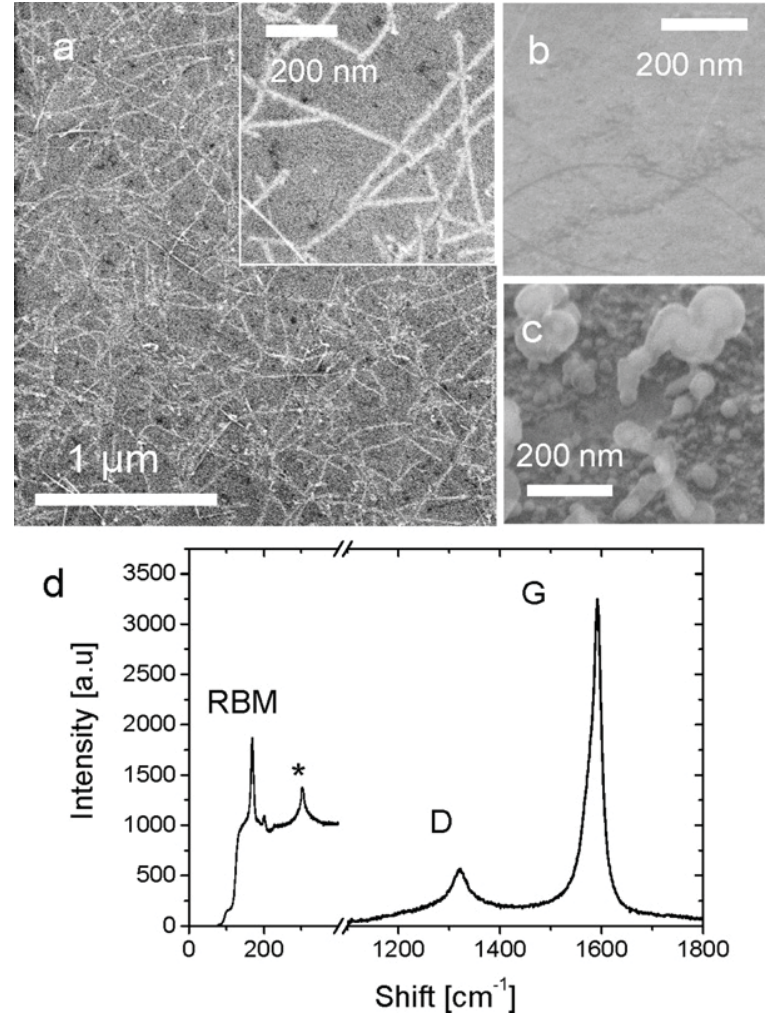

Fig. 2. SEM pictures (tilt $45^{\circ}$ ) of carbon structures synthesized at $800 \mathrm{C}$ using (a) $5.10^{-4} \mathrm{M}$, (b) $5.10^{-5} \mathrm{M}$ and (c) $5.10^{-3} \mathrm{M}$ solution of $\mathrm{FeCl}_{3} \cdot 6 \mathrm{H}_{2} \mathrm{O}$. (d) Raman spectra acquired on the CNT network obtained using $5 \cdot 10^{-4} \mathrm{M}$ solution of $\mathrm{FeCl}_{3} \cdot 6 \mathrm{H}_{2} \mathrm{O}$.

The organization of iron salt in ring shape after spraying is related to the well-known coffee-ring effect, which often occurs in printing technologies [16]. The solute (here iron salts) is deposited at the edge of the drying drop. We think that the first evaporated drops act as trapping site that stick further drops that hit the substrate. This could explain why discrete interlaced ring structure is observed for low concentration. As the concentration increases the density of defect site increases too, leading to higher deposit uniformity (Fig. 1c).

One of the advantages of the spraying technique for the preparation of the catalyst is the wide range of catalyst amount that could be deposited onto substrates. It can be simply adjusted by iron chloride solution concentration. For instance, very low density of catalyst could be easily prepared to grow low density 2-D network of CNTs. This contrasts with thin film dewetting process that generally requires very low initial thickness for such synthesis (typically $<1 \mathrm{~nm}$ ) and hence arises the question of the reproducibility of such preparation.

In order to find the optimized range of salt concentration that could yield in-plane CNT growth, we exposed a set of three samples prepared with $5.10^{-5} \mathrm{M}, 5.10^{-4} \mathrm{M}, 5.10^{-3} \mathrm{M}$ iron salt solution to high temperature CVD synthesis conditions (800 $\left.{ }^{\circ} \mathrm{C}\right)$. SEM images displayed in Fig. 2a revealed that well percolated carbon nanotubes 2-D network could be synthesized using intermediate $\mathrm{FeCl}_{3} \cdot 6 \mathrm{H}_{2} \mathrm{O}$ concentration $\left(5.10^{-4} \mathrm{M}\right)$. For lower concentration $\left(5.10^{-5} \mathrm{M}\right)$, only scarce carbon nanotubes can be distinguished on some area of the substrate (Fig. 2b). When higher concentration $\left(5.10^{-3} \mathrm{M}\right)$ is used, no more carbon nanotubes can be grown but only large iron particles surrounded by carbon are discerned (Fig. 2c).

Raman spectroscopy was carried out onto percolated CNT 2$\mathrm{D}$ network to give some insights on the structural features. $\mathrm{I}_{\mathrm{D}} / \mathrm{I}_{\mathrm{G}}$ intensity ratio, related to disorder in sp2 carbon network is estimate at 0.17 (Fig. 2d) which is low and typical to single-walled carbon
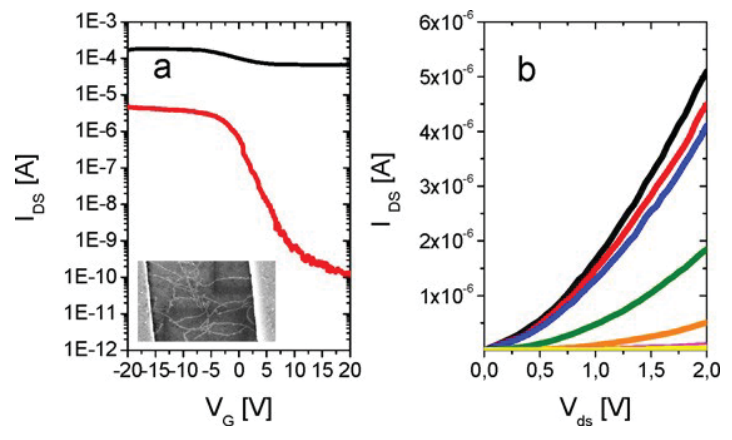

Fig. 3. (a) Transfer curves from SWCNT network based devices before (black line) and after (red line) an electrical breakdown process that eliminates metallic SWCNTs. The gap between interdigitated electrodes was $2 \mathrm{~J} . \mathrm{Lm}$ ((a) inset). (b) Current/voltage characteristic of same transistor: the gate voltage varied from $-20 \mathrm{~V}$ to $20 \mathrm{~V}$ from top to bottom (step: $4 \mathrm{~V}$ ). (For interpretation of the references to color in this figure legend, the reader is referred to the web version of the article.)

nanotubes [17]. The presence of strong radial breathing modes at low frequency $\left(\mathrm{cm}^{-1}\right)$ confirms that most of the network is made of single-walled carbon nanotubes.

Such percolated SWCNT networks are of great interest since they could behave as semiconducting channel for field effect transistor fabrication. To illustrate this potentiality, interdigitated electrodes made of $\mathrm{Ti}(5 \mathrm{~nm}) / \mathrm{Au}(35 \mathrm{~nm})$ (gap: $2 \mathrm{~J} . \mathrm{Lm}$ ) were deposited onto SWCNT samples grown on $\mathrm{Al}_{2} \mathrm{O}_{3}(100 \mathrm{~nm}) / \mathrm{SiO}_{2}(100 \mathrm{~nm}) / \mathrm{Si}(100 \mathrm{~nm})$ substrate. Typical transfer characteristics of such bottom gate devices are displayed in Fig. 3a. As-grown SWCNT network exhibit typical p-type response [1] with low $\mathrm{I}_{\mathrm{ON}} / \mathrm{I}_{\mathrm{OFF}}$ ratio of $\sim 2$ but relatively high "on" current: $\mathrm{I}_{\mathrm{ON}}=200$ J.LA (Fig. 3a - black line). This modest performance is explained by the presence of metallic nanotubes in the network (theoretically, one metallic SWCNT for two semiconducting ones [18]). In order to improve $\mathrm{I}_{\mathrm{ON}} / \mathrm{I}_{\mathrm{OFF}}$ ratio, samples were submitted to an electrical breakdown, consisting of a slow increase of $\mathrm{V}_{\mathrm{DS}}$ up to $45 \mathrm{~V}$ while keeping the device in "off” state $\left(V_{G}=20 \mathrm{~V}\right)$ [19]. After such a procedure, $\mathrm{I}_{\mathrm{ON}} / \mathrm{I}_{\mathrm{OFF}}$ ratio highly increases up to $5.10^{4}$ with a significant $\mathrm{I}_{\mathrm{ON}}$ of 5 J.LA. A detailed discussion of the electronic properties of these SWCNTs network will be given in further works since it is not the scope of the present paper.

In addition to 2-D SWNT networks, vertically aligned carbon nanotubes array (VACNT) is one of the most interesting CNT based architecture since it could yield breakthrough in various applications (super-capacitor, adhesive, lithium-ion batteries, chemical sensing, etc. $[4,20])$. In order to achieve such growth using spraying process, a set of three samples covered by $\mathrm{FeCl}_{3} \cdot 6 \mathrm{H}_{2} \mathrm{O}$ solution with various concentrations $\left(5.10^{-5} \mathrm{M}, 5.10^{-4} \mathrm{M}, 5.10^{-3} \mathrm{M}\right)$ was prepared and exposed to medium temperature CVD process $\left(600^{\circ} \mathrm{C}\right)$ for CNT growth.

As expected, the higher the iron salt concentration, the higher the resulting carbon nanotubes density. For low concentration $\left(5.10^{-5} \mathrm{M}\right)$, catalyst concentrates at the periphery of very rare ring structures. From such "coffee-ring" shape, very few nanotubes can be discerned. Using medium $\mathrm{FeCl}_{3} \cdot 6 \mathrm{H}_{2} \mathrm{O}$ concentration $\left(5.10^{-4} \mathrm{M}\right)$, "coffee-ring" effect is no more visible and uniform deposit of randomly organized CNTs is observed. As the $\mathrm{FeCl}_{3} \cdot 6 \mathrm{H}_{2} \mathrm{O}$ concentration increases up to $5.10^{-3} \mathrm{M}$, the resulting density of catalyst particles increases too and the CNTs preferentially grow vertically due to crowding effect. This typical CNT carpet-like architecture with length up to $\sim 7 \mathrm{~J} . \mathrm{Lm}$ is displayed in Fig. 4c.

Raman spectroscopy spectrum acquired on CNT arrays shows quite high $\mathrm{I}_{\mathrm{D}} / \mathrm{I}_{\mathrm{G}}$ ratio of 0.91 (Fig. $4 \mathrm{~g}$ - red line), which is typical of multi-walled carbon nanotubes, usually more defective as compared to single-walled CNTs. TEM study revealed that CNTs 

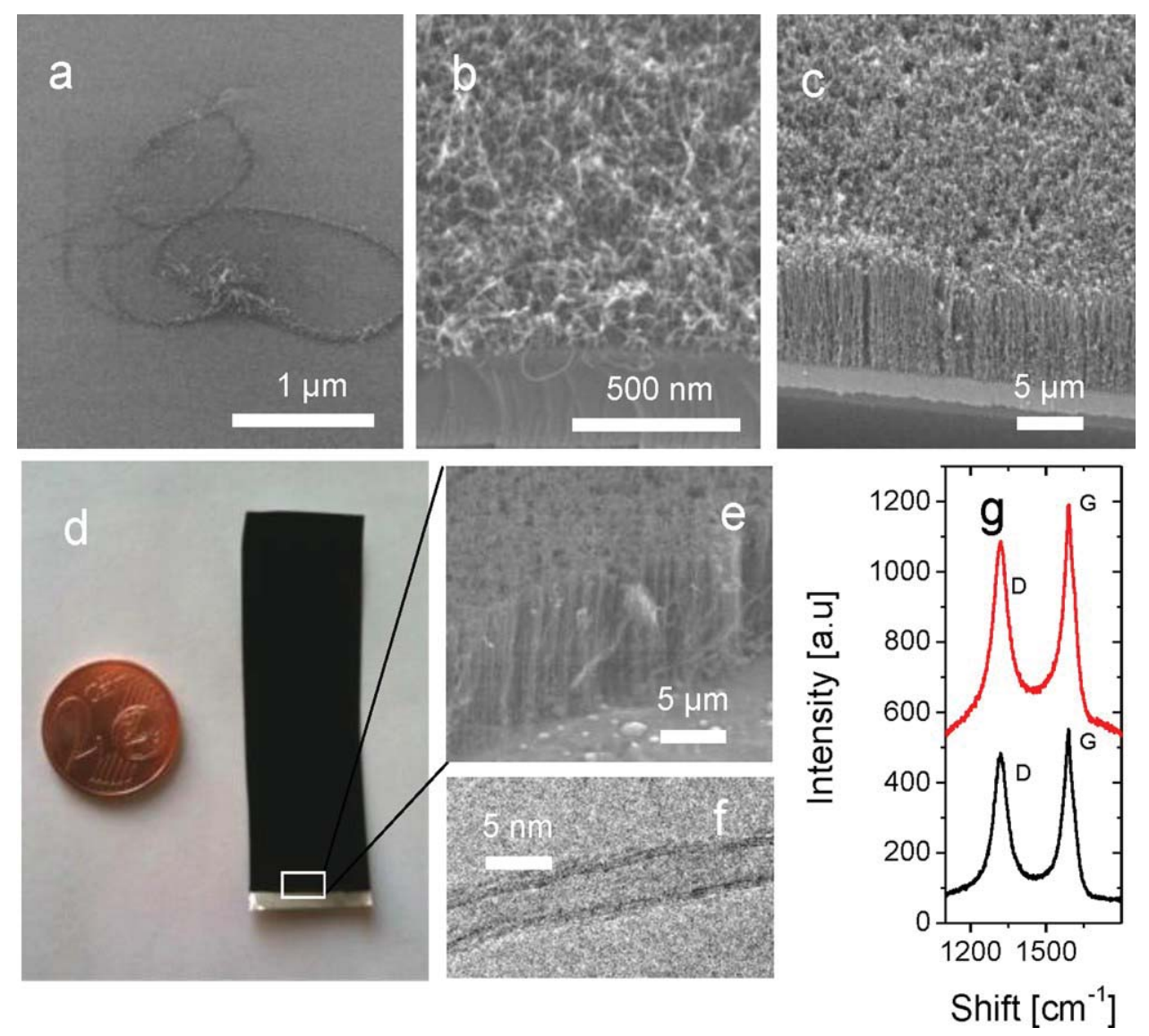

Fig. 4. SEM pictures (tilt $45^{\circ}$ ) of carbon structures synthesized at $600{ }^{\circ} \mathrm{C}$ using: (a) $5.10^{-5} \mathrm{M}$, (b) $5.10^{-4} \mathrm{M}$ and (c) $5.10^{-3} \mathrm{M}$ solution of $\mathrm{FeCl}_{3} \cdot 6 \mathrm{H}_{2} \mathrm{O}$. (d) Picture (e) $\mathrm{SEM}$ image and (f) TEM image of oriented carbon nanotubes grown on stainless steel foil ( $50 \mathrm{~mm} \times 17 \mathrm{~mm}$ ). (g) Raman spectra acquired on the CNT “carpet” grown on alumina (red line) and on aluminium covered steel foil (black line). (For interpretation of the references to color in this figure legend, the reader is referred to the web version of the article.)

are "few-walled carbon nanotubes" with typical diameter less than $10 \mathrm{~nm}$.

To illustrate the potentiality of spraying process for the elaboration of CNT array on large surface, we performed CNT growth on commercial 50 J.Lm thick iron steel foils (AISI 321; Goodfellow). Here, we use aluminum buffer layer $(20 \mathrm{~nm})$ instead of alumina in order to keep good electrical contact between CNTs and the substrate. Indeed, an electrical transparency between CNT and collector is often required for most of VACNT based applications. As shown in the literature, aluminium can also provide optimized catalyst/support interaction for the growth of vertically aligned CNTs $[13,21]$. Fig. $4 d$ shows the vertically aligned CNTs carpet onto $50 \mathrm{~mm} \times 17 \mathrm{~mm}$ steel foil. These CNTs exhibit same morphological features in terms of length (Fig. 4e) and diameter (Fig. 4f) as well as same Raman signature (Fig. $4 \mathrm{~g}$ - black line) as compared to VACNTs synthesized on alumina. Further works will be dedicated to their use as nanostructured electrodes in lithium-ion batteries application.

\section{Conclusion}

In conclusion, we have developed a low-cost process based on aerosol spray to prepare catalyst for the synthesis of carbon nanotubes. This technique was shown to be very versatile since 2-D single walled carbon nanotubes networks as well as for vertically aligned CNT array could be synthesized on large surface. We emphasize that this approach combines both the advantages of inorganic chemistry in terms of variety of compounds that can be studied and thin film processing. Further improvement in the control of CNT structure could be provided by studying salt mixture.

\section{References}

[1] Q. Cao, J.A. Rogers, Ultrathin films of single-walled carbon nanotubes for electronics and sensors: a review of fundamental and applied aspects, Adv. Mater. 21 (2009) 29-53.

[2] W.I. Milne, K.B.K. Teo, G.A.J. Amaratunga, P. Legagneux, L. Gangloff, J.-P. Schnell, V. Semet, V. Thien Binh, O. Groening, Carbon nanotubes as field emission sources, J. Mater. Chem. 14 (2004) 933.

[3] D.R. Kauffman, A. Star, Carbon nanotube gas and vapor sensors, Angew. Chem. Int. Ed. 47 (2008) 6550.

[4] H. Zhang, G. Cao, Y. Yang, Carbon nanotube arrays and their composites for ectrochemical capacitors and lithium-ion batteries, Energy Environ. Sci. 2 (2009) 932.

[5] S. Ijima, Helical microtubules of graphitic carbon, Nature 354 (1991) 56.

[6] G. Lolli, L. Zhang, L. Balzano, N. Sakulchaicharoen, Y. Tan, D.E. Resasco, Tailoring $(n, m)$ structure of single-walled carbon nanotubes by modifying reaction conditions and the nature of the support of CoMo catalysts, J. Phys. Chem. B 110 (2006) 2108.

[7] T. Yamada, T. Namai, K. Hata, D.N. Futaba, K. Mizuno, Size-selective growth of double-walled carbon nanotube forests from engineered iron catalysts, Nat. Nanotechnol. 1 (2006) 131.

[8] S. Hofmann, R. Blume, C.T. Wirth, M. Cantoro, R. Sharma, C. Ducati, M. Hvecker, S. Zafeiratos, P. Schnoerch, A. Oestereich, D. Teschner, M. Albrecht, A. KnopGericke, R. Schlgl, J. Robertson, State of transition metal catalysts during carbon nanotube growth, J. Phys. Chem. C 113 (2009) 1648.

[9] H.C. Choi, S. Kundaria, D. Wang, A. Javey, Q. Wang, M. Rolandi, H. Dai, Efficient formation of iron nanoparticle catalysts on silicon oxide by hydroxylamine for carbon nanotube synthesis and electronics, Nano Lett. 3 (2003) 157.

[10] H. Kind, J.-M. Bonard, L. Forro, K. Kern, Printing gel-like catalysts for the directed growth of multiwall carbon nanotubes, Langmuir 16 (2000) 6877.

[11] A.M. Cassell, S. Verma, L. Delzeit, M. Meyyappan, J. Han, Combinatorial optimization of heterogeneous catalysts used in the growth of carbon nanotubes, Langmuir 17 (2001) 260. 
[12] B.H. Hong, J.Y. Lee, T. Beetz, Y. Zhu, P. Kim, K.S. Kim, Quasi-continuous growth of ultralong carbon nanotube arrays, J. Am. Chem. Soc. 127 (2005) 15336.

[13] C. Emmenegger, P. Mauron, A. Züttel, C. Nützenadel, A. Schneuwly, R. Gallay, L. Schlapbach, Carbon nanotube synthesized on metallic substrates, Appl. Surf. Sci. 452 (2000) 162.

[14] F.Z. Bouanis, L. Baraton, V. Huc, D. Pribat, C.S. Cojocaru, High-quality singlewalled carbon nanotubes synthesis by hot filament CVD on Ru nanoparticle catalyst, Thin Solid Films 519 (2011) 4594.

[15] N.S. McIntyre, D.G. Zetaruk, X-ray photoelectron spectroscopic studies of iron oxides, Anal. Chem. 49 (1977) 1521.

[16] H. Hu, R.G. Larson, Marangoni effect reverses coffee-ring depositions, J. Phys. Chem. B 110 (2006) 7090
[17] M.S. Dresselhaus, G. Dresselhaus, R. Saito, A. Jorio, Raman spectroscopy of carbon nanotubes, Phys. Rep. 409 (2005) 47.

18] M.S. Dresselhaus, G. Dresselhaus, R. Saito, Physics of carbon nanotubes, Carbon 33 (1995) 883.

[19] P.G. Collins, M.S. Arnold, P. Avouris, Engineering carbon nanotubes and nanotube circuits using electrical breakdown, Science 292 (2001) 706.

[20] L. Ge, S. Sethi, L. Ci, P.M. Ajayan, A. Dhinojwala, Carbon nanotube-based synthetic gecko tapes, Proc. Natl. Acad. Sci. U.S.A. 104 (2007) 10792.

[21] C. Li, Y. Zhang, M. Mann, D. Hasko, W. Lei, B. Wang, D. Chu, D. Pribat, G.A.J. Amaratunga, W.I. Milne, High emission current density, vertically aligned carbon nanotube mesh, field emitter array;, Appl. Phys. Lett. 97 (2010) 113107. 